\title{
IT and Competitive Advantage: A Study from Micro Perspective
}

\author{
Jiayu Chi', Ling Sun ${ }^{2}$ \\ ${ }^{1}$ School of Business, Sun Yat-sen University, Guangzhou, China \\ ${ }^{2}$ Lingnan College, Sun Yat-sen University, Guangzhou, China \\ Email: chijiayu@mail.sysu.edu.cn
}

Received 24 February 2015; accepted 18 March 2015; published 24 March 2015

Copyright (C) 2015 by authors and Scientific Research Publishing Inc.

This work is licensed under the Creative Commons Attribution International License (CC BY). http://creativecommons.org/licenses/by/4.0/

(c) (i) Open Access

\begin{abstract}
The relationship of the IT and competitive advantage is a hot research topic for a long time. Based on existing research, this paper proposes an integrated procedure model of how IT impacts firm's competitive advantage. The model provides an integrated framework for the study of the relationship of the IT and competitive advantage, and can provide effective guidance for firms to use IT to obtain sustainable competitive advantage.
\end{abstract}

Keywords

Information Technology, Competitive Advantage, IT Capability

\section{Introduction}

Currently more and more firms recognize the great advantages and potentials of information technology (IT), and are investing heavily in information technology. Despite considerable success and great progress have been made in Chinese firm's IT project practices, the overall the situation is not optimistic, the failure rate of IT projects remains high, and the actual earnings are far below the expected return from IT projects.

The relationship between IT and competitive advantage has been the academic focus of attention and debate issues. Although many researchers found that IT investments contribute to help firms gain competitive advantage [1]-[3], the voice of doubt has not been stopped, of which the most famous are the Solow computer paradox in reference to Robert Solow's 1987 quip, "You can see the computer age everywhere but in the productivity statistics”, and Carr's point of view "IT doesn't matter" [4] [5]. Therefore, the study of the relationship between IT and competitive advantage has great theoretical significance and important practical value for guiding firms to use IT to obtain sustainable competitive advantage.

Many scholars studied the relationship between IT and competitive advantage based on process theory, 
complementary asset theory, IT resource theory, IT capability theory, etc. Based on these researches, this paper proposes an integrated procedure model of how IT impacts firm's competitive advantage. The model provides a uniform framework for the study of the impact of IT on competitive advantage.

\section{The Impact of IT on Competitive Advantage}

\subsection{The Market-Based View (MBV)}

From the early 1980s, the analysis of the relationship between IT and competitive advantage mainly uses the Market-Based View of strategy theory, which argues that industry factors and external market orientation are the primary determinants of firm performance [6]-[9]. According Bain's Structure-Conduct-Performance (SCP) framework [6] and Porter's five forces model [8], which are two of the best-known theories in the Market-Based View of strategy theory, many scholars believe that the extensive application of IT will cause more intense competition among firms, and IT can bring firms competitive advantage by enhancing their ability to take advantage from opportunities, defend against threats, and change their market position.

But there are also some scholars proposed IT will not bring competitive advantage for firms. Hitt and Brynjolfsson found that IT can increase productivity and create substantial value for consumers, but there is no evidence that these benefits have resulted in supernormal business profitability [10]. Carr argued that the strategic importance of IT in business has diminished as IT has become more commonplace [5].

\subsection{The Resource-Based View (RBV)}

Furrer et al. suggested that since the 1980s onwards, the focus of studies on competitive advantage has changed from the structure of the industry (MBV) to the firm's internal structure, with resources and capabilities [11]. This approach to strategy is known as the Resource-Based View (RBV), which draws attention to the firm's internal environment as a driver for competitive advantage and emphasizes the resources that firms have developed to compete in the environment. Applying Barney's VRIN framework can determine if a resource is a source of sustainable competitive advantage. To serve as a basis for sustainable competitive advantage, resources must be valuable, rare, in-imitable, non-substitutable [12].

According to VRIN framework, IT can not bring the sustainable competitive advantage directly for firms, due to its non-scarcity and replicability. But if IT can closely integrated with business strategy, organizational processes, and other internal and external resources, which has path dependency, causal ambiguity and social complexity, and is difficult to be imitated and copied by a competitor.

In summary, most scholars believe that IT can help firms obtain sustainable competitive advantage. The next sections will discuss the mechanisms IT affects the competitive advantage and how firms should use IT to gain competitive advantage.

\section{How IT Affects Competitive Advantage}

In the existing literature, studies on how IT affect firm's competitive advantage are mostly based on process theory, complementary asset theory, IT resource theory, IT capability theory. These theories based on or impacted by RBV.

\subsection{Process Theory}

Markus and Soh proposed IT investment can not improve firm performance directly. To improve performance, firms need turn IT spending into useful and potentially produce IT assets firstly, and then use of these IT assets to help firms improve their performance [13]. They further proposed the process theory, which consists of three sub-processes: 1) the IT conversion process; 2) the IT use process; 3 ) the competitive process (shown as Figure 1) [14].

Firstly, through "the IT conversion process" firms should take some IT management activities, which convert IT investments into IT assets; Then, through "the IT use process", firms can use IT assets to obtain the corresponding IT impacts, such as the development of new products or services, business process reengineering, improve decision-making, coordination and flexibility; Finally, whether the IT impacts can improve firm performance depends on firm's "the competitive process" [14]. Even if the firm has made some good IT impact, but if it can 


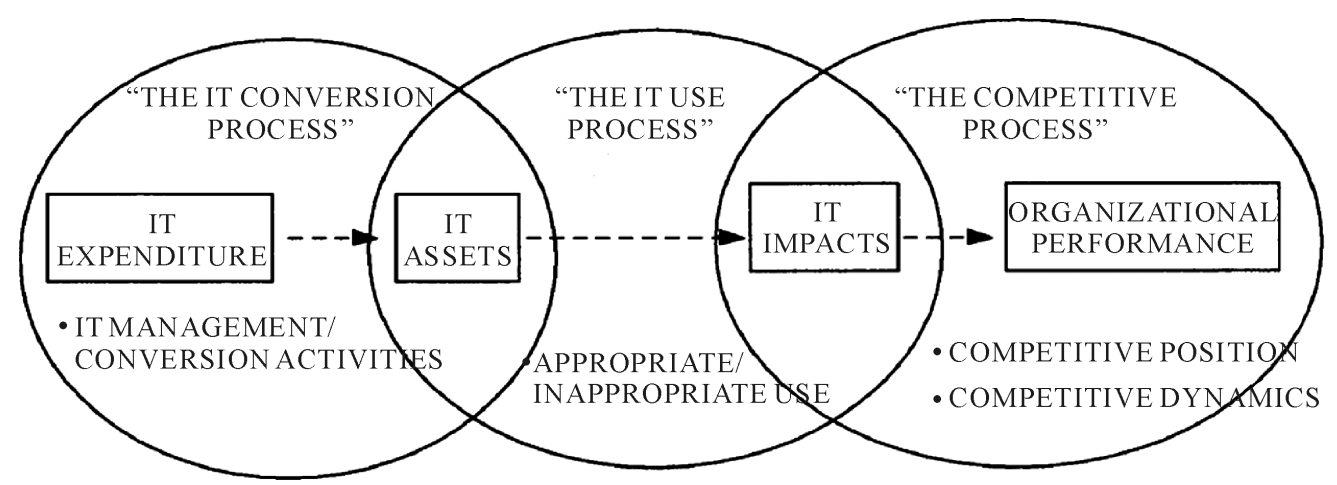

Figure 1. Soh and Markus’s process model of how IT creates business value.

not win the competition with other competitors, it will be unable to get the improvement of performance.

\subsection{Complementary Asset Theory}

Complementary assets are those assets required to derive value from a primary investment [15]. Complementary asset theory indicates that IT alone can not help firms to achieve sustainable competitive advantages, but firms can gain advantages by using IT to leverage firm's complementary assets such as new business models, new business processes, management behavior, organizational culture, or training. Related research shows that firms that support their IT investments with the investments in complementary assets receive superior returns, whereas those firms failing to make these complementary investments receive less or no returns on their IT investments [16] [17]. Powell and Micallef found IT resources and the complementary role of human resources and business resources (such as flexible culture, strategic planning-IT integration, and supplier relationships) can explain the performance differences between firms in retail industry [18]. Teo and Ranganathan also found the synergy among IT resources, human resources and business resources can lead to improved organizational performance [19].

\subsection{IT Resource Theory}

Based on RBV, some scholars proposed the concept of "IT resources", and argued that the heterogeneous IT resources of firms are the basis to gain competitive advantage. Mata et al. discussed four IT resources, which are capital requirements, proprietary technology, technical IT skill, and managerial IT skill, and they concluded that managerial IT skill is the only one that can provide sustainable competitive advantages from this resource-based view [20]. Qi et al. indicated that in order to obtain competitive IT resources, it takes a considerable amount of time and effort to learn and accumulate [21]. Due to the path dependency, causal ambiguity and social complexity of IT resources, it is difficult to imitate and copy. So IT resources can be a source of competitive advantage [21].

\subsection{IT Capability Theory}

With the development of core competence theory, dynamic capability theory and organizational learning theory, more and more scholars believe that IT resources can not provide firms sustainable competitive advantage by itself, and the "IT capabilities" (the ability to deploy IT resources [22]) is one of the decisive factors to help firms gain a long-term competitive advantage. Ross et al. first proposed the concept of the earlier IT capability, they defined IT capabilities as "the ability to control IT-related costs, deliver systems when needed, and affect business objectives through IT implementations". And they consider the ability to use IT to capture fleeting business opportunities can bring success for a firm [23]. Wade et al. considered the role of IT capability for competitive advantage is not directly, but it can affect firm's competitive activities to form a complex chain of assets and capabilities, and ultimately bring the sustainable competitive advantage for firm [24]. Some scholars explored the mechanisms of IT capabilities affecting competitive advantage from different perspective, such as organizational learning, knowledge management, core competencies and information synergy [25]-[28]. 


\section{The Process Model of How IT Impacts Firm's Competitive Advantage}

Based on existing research, we propose an integrated process model of how IT impacts firm's competitive advantage, as shown in Figure 2.

Major improvements and features of the model include:

1) It is a comprehensive model that integrated process theory, complementary asset theory, IT resource theory, IT capability theory, and organizational learning theory.

The four theories presented in last section have important theoretical and practical value to investigate how IT affect competitive advantage, but each of these theories focuses only on one aspect of IT's role on competitive advantage, lack of relevant research on the relationship between these theories. The process model proposed by this paper is based on Soh's process model of how IT creates business value [14], and combines the concepts and principles of complementary asset theory, IT resource theory, IT capability theory and organizational learning theory. So it's an extension of existing theories. This model not only provides a unified analytical framework on the problem of how IT impacts competitive advantage, but also can better guide firms to use IT to obtain sustainable competitive advantage.

2) Replaces "IT assets” in Soh’s process model by "IT resources"

Soh and Markus took into account the fact that IT investment is likely to be wasted due to poor management, so they proposed "IT assets" as a mediating variable between IT expenditure and organizational performance to reflect the conversion efficiency of IT investments [14]. They defined "IT assets" as a combination of IT infrastructure (including soft infrastructure such as expertise and experience) and a portfolio of applications. Then IT resources theory put forward the concept of "IT resources", and proposed that the heterogeneous IT resources have been the basis for firms to gain competitive advantage. "IT resources" actually expand the concept of "IT assets", which not only contains all the connotation of "IT assets" and also added "IT intangible resources" and "IT relations resources" and other connotations, to better reflect the results of IT investments. Therefore, the paper replaces "IT assets" by "IT resources" in the process model.

3) IT capability plays an important moderate role in the "IT conversion process" and "IT use process"

This paper adopts Bharadwaj's definition of IT capability-its ability to mobilize and deploy IT-based resources in combination or copresent with other resources and capabilities [22]. Because IT capabilities are closely linked with the history, culture and experience of firms, so they are more difficult to be copied or imitated by competitors than IT resources, and can help firms gain sustainable competitive advantage. Firms with superior IT capabilities can not only improve the efficiency of IT investments into IT resources, but also can integrate firm's IT resources with other complementary resources, to achieve a sustainable competitive advantage for the firms. Therefore, the process model takes the IT capabilities as a moderate variable in the "IT conversion process" and "IT use process".

4) Good organization learning capability can enhance and update the IT capability

Although the resource-based theory elaborates the relationship between firm's resources and competitive advantage, and provides a good framework for the study of the relationship between IT and competitive advantage theory, but the resource-based theory considers less external environment factors for firms, it is difficult to fully explain the issues of obtaining and maintaining competitive advantage in a rapidly changing business environment [29]. "Organization learning capability” is more and more important for firms, which can help firms constantly

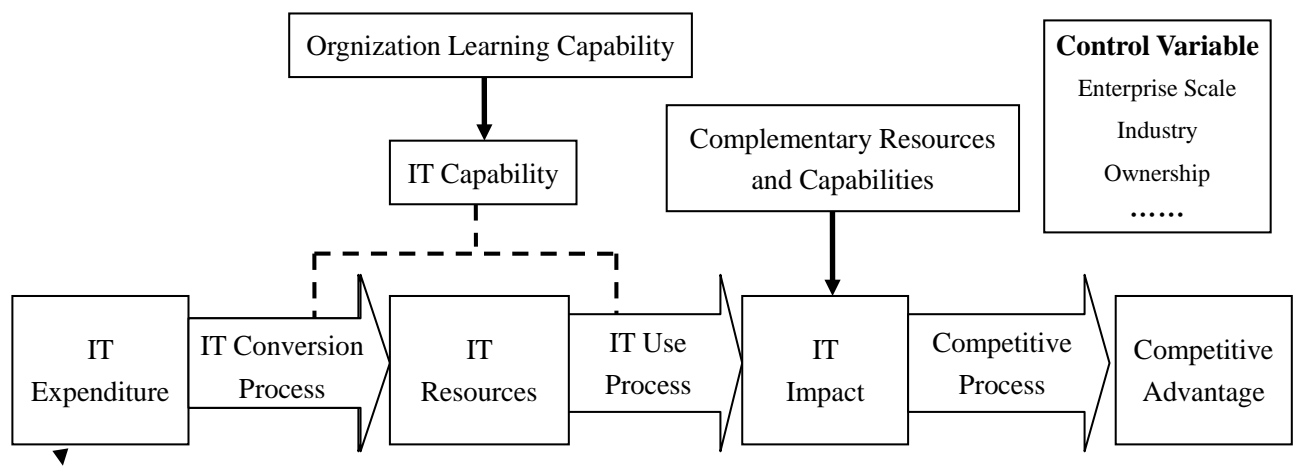

Figure 2. The process model of how IT impacts firm's competitive advantage. 
adjust and adapt in an environment of intense competition and rapid change in order to maintain their competitive advantage. “Organization learning capability” refers to the organization's ability to absorb knowledge, create knowledge and apply knowledge. Bhatt's empirical researches have confirmed that the "organizational learning capability" has important influence on the constantly upgrading and updating the IT capability of firms [30]. This paper introduces the "organizational learning capability" into the process model of how IT impacts firm's competitive advantage that can better guide firms to use IT to help firms build and maintain a competitive advantage in a rapidly changing environment.

\section{Implications for Management}

1) Judge whether a firm has the prerequisite to use of IT to obtain sustainable competitive advantage

Firstly, firms need to analyze what are the main problems and challenges they face and need to solve, and whether IT can help them address these problems and challenges. Need to be aware is that IT cannot immediately solve all problems of firms, such as insufficient production capacity, low brand awareness, and so on. Secondly, if firms are sure IT can help them address these issues, then the next, firms need to determine whether now is the right time for using IT to help them address these issues. In General, when a firm in a period of relatively stable development, external competition and environmental change is not dramatic, and it's early IT project was completed and achieve the expected results, it is suitable for implementing a new IT project. Finally, firms need to judge whether they have enough resources and capabilities (such as financial, human, IT capabilities, etc.) to implement a new project. If firms lack the resources and capacity, they may consider recruiting personnel, outsourcing IT projects or adopting IT services solutions. Only on the premise of guaranteed sufficient resources and capacity, an IT project can succeed.

2) Cultivate firm's IT capabilities through organizational learning

IT capability plays an important moderate role in the "IT conversion process" and "IT use process". The stronger IT capability the firm has, the more effective IT investments will convert into IT resources and the better the firm use of IT resources to help improve performance. Therefore, firms should constantly improve and update their IT capabilities, and organizational learning will play a very important role in this process. Organizational learning mainly enhances firm's IT capabilities through training and project practice. Effective training can undoubtedly enhance staff's IT technical capacity and IT management capabilities. Especially with the wide use of Internet and Intranet technologies in firms, online training has become an important way of training. In addition to training, project practice is another effective way of organizational learning. Employees can not only "learning by doing" (including self-study in the project practice, mutual learning among colleagues, learning from outside experts and consultants, etc.), and can also strengthen relationships with colleagues, customers and external partners through the project practice and collaboration.

3) Focusing on investment in complementary resources

IT resources alone does not guarantee a firm to gain competitive advantage, therefore firm should not only invest in IT resources, but also pay attention to invest in the corresponding complementary resources, such as the organization's business processes and regulations system.

Firstly, firms need to digitize and optimize their business processes to achieve business process automation and visualize, that can not only improve the efficiency of firms, but the key is to enable firms to rapidly perceived customer needs and the variety of internal and external changes and problems, and make timely response.

Secondly, firms should establish an appropriate rules and regulations system, including the authorization of employees and reasonable incentives. Employees should be granted access to more of the required information and use that information and give them the right to make decisions, this will help to establish a flat corporate structure in order to reduce administrative costs and improve the speed of decision-making. Meanwhile, firms should establish reasonable performance-based salary system to motivate employees to use the right of information access and decision-making to complete their work more outstanding and creatively.

\section{Conclusions}

This paper proposed an integrated process model of how IT impacts firm's competitive advantage, based on the process theory, complementary asset theory, IT resource theory, IT capability theory, and organizational learning theory. The model suggests that IT capability plays an important moderate role in the "IT conversion process" and "IT use process", firms should constantly improve and update their IT capabilities through organizational 
learning, and pay more attention to develop corresponding complementary resources, such as organization's business processes and culture. This model not only provides an explanation of how IT brings competitive advantage, but also can provide effective guidance for firms to use IT to obtain sustainable competitive advantage.

In the future, the model proposed by this paper can be extended by other theories and research, and more empirical studies are needed to check this model.

\section{Funding}

This work was supported in part by NSFC under Grant Nos. 70902025 and 91124004, Guangdong soft science project under Grant Nos. 2010B070300043.

\section{References}

[1] Clemons, E.K. and Row, M.C. (1991) Sustaining IT Advantage: The Role of Structural Differences. MIS Quarterly, 15, 275-292. http://dx.doi.org/10.2307/249639

[2] Quan, J.J., Hu, Q. and Hart, P.J. (2003) Information Technology Investments and Firms' Performance-A Duopoly Perspective. Journal of Management Information Systems, 20, 121-158.

[3] Wang, M.J., Zhang, W.Y. and Zhou, L.A. (2007) Informationization, the Organizational Behavior and Performance: A Case Study Based On Zhejiang’s Enterprises. Management World, 4, 96-104, 129.

[4] Solow, R. (1987) We'd Better Watch Out. New York Times Book Review, 7, 1.

[5] Carr, N.G. (2003) IT Doesn’t Matter. Harvard Business Review, 81, 41-49.

[6] Bain, J. (1968) Industrial Organization. John Wiley and Sons, New York.

[7] Peteraf, M.A. and Bergen, M.E. (2003) Scanning Dynamic Competitive Landscapes: A Market-Based and ResourceBased Framework. Strategic Management Journal, 24, 1027-1041. http://dx.doi.org/10.1002/smj.325

[8] Porter, M.E. (1980) Competitive Strategy: Techniques for Analysing Industries and Competitors. Free Press, New York.

[9] Porter, M.E. (1996) What Is Strategy? Harvard Business Review, 74, 61-78.

[10] Brynjolfsson, E. and Hitt, L. (1996) Paradox Lost? Firm-Level Evidence on the Returns to Information Systems Spending. Management Science, 42, 541-558. http://dx.doi.org/10.1287/mnsc.42.4.541

[11] Furrer, O., Thomas, H. and Goussevskaia, A. (2008) The Structure and Evolution of The Strategic Management Field: A Content Analysis of 26 Years of Strategic Management Research. International Journal of Management Reviews, 10, 1-23. http://dx.doi.org/10.1111/j.1468-2370.2007.00217.x

[12] Barney, J. (1991) Firm Resources and Sustained Competitive Advantage. Journal of Management, 17, 99-120. http://dx.doi.org/10.1177/014920639101700108

[13] Markus, M.L. and Soh, C. (1993) Banking on Information Technology: Converting IT Spending into Firm Performance. Strategic Information Technology Management: Perspectives on Organizational Growth and Competitive Advantage. IGI Publishing, Hershey.

[14] Soh, C. and Markus, M.L. (1995) How IT Creates Business Value: A Process Theory Synthesis. Proceedings of the 6th International Conference on Ion Sources (ICIS 1995), Whistler, Canada, 10-16 September 1995, 29-41.

[15] Teece, D.J. (1986) Profiting from Technological Innovation: Implications for Integration, Collaboration, Licensing and Public Policy. Research Policy, 15, 285-305. http://dx.doi.org/10.1016/0048-7333(86)90027-2

[16] Brynjolfsson, E. and Hitt, L.M. (2000) Beyond Computation: Information Technology, Organizational Transformation, and Business Performance. Journal of Economic Perspectives, 14, 23-48. http://dx.doi.org/10.1257/jep.14.4.23

[17] Davern, M.J. and Kauffman, R.J. (2000) Discovering Potential and Realizing Value form Information Technology Investments. Journal of Management Information Systems, 16, 121-143.

[18] Powell, T.C. and Dent-Micallef, A. (1997) Information Technology as Competitive Advantage: The Role of Human, Business, and Technology Resources. Strategic Management Journal, 18, 375-405. http://dx.doi.org/10.1002/(SICI)1097-0266(199705)18:5<375::AID-SMJ876>3.0.CO;2-7

[19] Teo, T.S.H. and Ranganathan, C. (2003) Leveraging IT Resources and Capabilities at the Housing and Development Board. The Journal of Strategic Information Systems, 12, 229-249. http://dx.doi.org/10.1016/j.jsis.2003.09.002

[20] Mata, F.J., Fuerst, W.L. and Barney, J.B. (1995) Information Technology and Sustained Competitive Advantage: A Resource-Based Analysis. MIS Quarterly, 19, 487-505. http://dx.doi.org/10.2307/249630

[21] Qi, X.F. and Lan, B.X. (2006) IT Resources and Sustainable Competitive Advantage: From the Firm Resource-Based View. Journal of Tsinghua University (Science and Technology), 46, 930-935. 
[22] Bharadwaj, A.S. (2000) A Resource-Based Perspective on Information Technology Capability and Firm Performance: An Empirical Investigation. MIS Quarterly, 24, 169-196. http://dx.doi.org/10.2307/3250983

[23] Ross, J.W., Beath, C.M. and Goodhue, D.L. (1996) Develop Long-Term Competitiveness through Information Technology Assets. Sloan Management Review, 38, 31-42.

[24] Wade, M. and Hulland, J. (2004) Review: The Resource-Based View and Information Systems Research: Review, Extension, and Suggestions for Future Research. MIS Quarterly, 1, 107-142.

[25] Huang, Y.H., Li, E.Y. and Chen, J.S. (2009) Information Synergy as the Catalyst between Information Technology Capability and Innovativeness: Empirical Evidence from the Financial Service Sector. Information Research-An International Electronic Journal, 14.

[26] Ravichandran, T. and Lertwongsatien, C. (2005) Effect of Information Systems Resources and Capabilities on Firm Performance: A Resource-Based Perspective. Journal of Management Information Systems, 21, 237-276.

[27] Ray, G., Muhanna, W.A. and Barney, J.B. (2005) Information Technology and the Performance of the Customer Service Process: A Resource-Based Analysis. MIS Quarterly, 29, 625-652.

[28] Tippins, M.J. and Sohi, R.S. (2003) IT Competency and Firm Performance: Is Organizational Learning a Missing Link? Strategic Management Journal, 24, 745-761. http://dx.doi.org/10.1002/smj.337

[29] Teece, D.J., Pisano, G. and Shuen, A. (1997) Dynamic Capabilities and Strategic Management. Strategic Management Journal, 18, 509-533. http://dx.doi.org/10.1002/(SICI)1097-0266(199708)18:7<509::AID-SMJ882>3.0.CO;2-Z

[30] Bhatt, G.D. and Grover, V. (2005) Types of Information Technology Capabilities and Their Role in Competitive Advantage: An Empirical Study. Journal of Management Information Systems, 22, 253-277. 